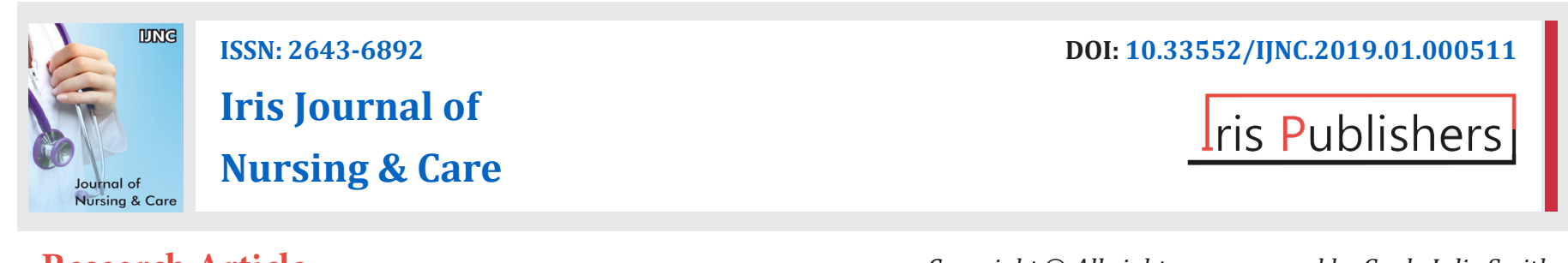

Research Article

Copyright (C) All rights are reserved by Gayle Julie Smith

\title{
Improving Specialty Care to the Medically Underserved
}

\author{
Gayle Julie Smith* \\ Doctor of Nursing Practice, Northwestern State University, USA
}

*Corresponding author: Gayle Julie Smith, Doctor of Nursing Practice,

Northwestern State University, USA.

Received Date: January 16, 2019

Published Date: February 26, 2019

\begin{abstract}
The purpose of the Doctor of Nursing Practice (DNP) scholarly project was implementation of a clinical practice change, use of a DNP student developed patient referral form (PRF), and evaluate medically underserved (MU) patients' access to and utilization of specialty care services. The major objectives of the scholarly project were to evaluate if PRF implementation improved MU patients' access to or utilization of specialty care services in an urban community health center (CHC), and to identify barriers to patients utilizing prescribed specialty care services. Donabedian's Model guided the quality improvement project that utilized data from a retrospective chart review to evaluate an urban CHC's specialty care referral process before and after the implementation of a DNP student developed PRF ( $N=48)$. The DNP student observed for any difference in MU's access and utilization of specialty care services after a clinical practice change implementing the patient referral form. Further, the DNP student evaluated potential causes of MU patients not utilizing the prescribed specialty care services. Data analysis showed that there was no statistically significant difference in specialty care access $(\chi 2(1)=.000, p>.05)$ and utilization $(\chi 2(1)=1.4182, p=0.2337)$ after the implementation of a DNP student developed patient referral form. The primary reason MU patients cited as not utilizing specialty care services was lack of knowledge about the appointment. Additional data analysis showed that MU patients who were referred for breast services received appointments at a statistically significantly higher rate than all other specialties $(\chi 2(3)=8.800, p=0.0321)$. The initial assumption of the DNP student was that specialty care services were not readily accessible to the MU population. However, the results of the scholarly projected refuted this assumption as specialty care services were found to be available to the MU population. However, the services were often not utilized due to a breakdown in the referral process. The use of system-based approaches can improve the coordination and delivery of specialty care services. Doctor of Nursing Practice (DNPs) can address challenges to healthcare access and utilization by supporting patients' navigation through the complex healthcare system.

Abbreviations: DNP: Doctor of Nursing Practice; PRF: Patient Referral Form; MU:Medically Underserved; CHC: Community Health Center; ACA: Affordable Care Act; IOM: Institute of Medicine; FQHCs: Federally Qualified Health Centers; CHCs: Community Health Centers; SFGH: San Francisco General Hospital and Trauma Center; HIV: Human Immunodeficiency Virus; STI: Sexually Transmitted Infection; FPL: Federal Poverty Level
\end{abstract}

\section{Introduction}

Today's complex and evolving healthcare system is facing many challenges. Innovative and sustainable solutions are needed to meet the challenge of delivering quality, accessible, cost-efficient healthcare to all Americans. Advanced practice registered nurses have the opportunity to meet this need for increased access and improved quality of healthcare.

Healthcare reform, specifically the implementation of the Patient Protection and Affordable Care Act (ACA), was proposed as the solution to the challenge of accessible, affordable healthcare. Although the ACA has not yet proven to be the complete solution to the provision of healthcare for all Americans, it has ignited a vision to make healthcare available to all Americans. To further this vision of Americans having affordable, accessible healthcare, quality improvement initiatives to make healthcare more patient centered, reliable, accessible, and safe are needed. The initiation and evaluation of quality improvement scholarly projects, that improve healthcare outcomes, are an essential component of the Doctor of Nursing (DNP) degree. This paper, which describes implementation and evaluation of a DNP scholarly project, begins with a brief description of issues surrounding healthcare access. Next, the theoretical framework is described. Chapter one then 
presents the purpose and significance of the scholarly project and concludes with a description of the project's limitations and assumptions.

\section{Background of the clinical problem}

The purpose of the DNP scholarly project is to engage the DNP student in implementation of an evidence-based solution to a clinical practice problem which improves healthcare outcomes and contributes to nursing's body of knowledge. The background of the clinical problem provides the reader with insight into historical, political, and economical aspects surrounding the clinical problem. Additionally, the background section of the paper thoroughly describes the chosen phenomenon of interest [1]. The major phenomena of interest for this DNP scholarly project were: (a) healthcare affordability and access; (b) community health centers' role in meeting the healthcare needs of the medically underserved; and, (c) coordination of specialty care services for the medically underserved.

For the past few decades, improvement of healthcare quality and increased access to healthcare services have been on the political forefront of healthcare reform. As predicted, the ACA sharply decreased the number of uninsured Americans from 2013 to 2014 [2]. However, despite the ACA's impact on reducing America's health insurance coverage gap, healthcare coverage remains unpredictable. Many American families lose and gain healthcare insurance coverage within a given year. Often the loss of healthcare insurance is due to a change in employment status. Even when employment insurance coverage or insurance through the ACA is available, many Americans cannot afford the premiums. The rising cost of insurance premiums and deductibles has driven many healthcare consumers to pay the monetary penalty associated with not purchasing health insurance coverage, rather than purchasing health insurance. The problems of access and affordability render many Americans and their families in need of healthcare services [3-5]. However, lack of healthcare insurance coverage is not the only barrier to healthcare access. Cultural, linguistic, and geographic issues are additional barriers to healthcare access. Accessing healthcare providers who understand a patient's culture and language, as well as finding transportation to healthcare facilities often proves difficult, especially for those without healthcare insurance. In fact, entire American communities lack access to healthcare resources because of geographic location and lack of insurance. These communities, composed of individuals lacking both health insurance and access to healthcare resources, are defined as the medically underserved (MU) (Health Resources and Services Administration (HRSA), 2014; National Association of Community Health Centers (NACHC), 2014).

To meet the healthcare needs of the MU, many communities rely on safety net healthcare practices. As defined by the Institute of Medicine (IOM) (2000), safety net practices include "those providers that organize and deliver a significant level of health care and other needed services to the uninsured, Medicaid and other vulnerable patients" (p. 21). Safety net providers include public hospital systems, state and locally supported community health centers (CHCs), Federally Qualified Health Centers (FQHCs), local health departments and charitable health programs [6]. As a critical component of the nation's healthcare safety net, CHCs have strived for decades to meet the MU's healthcare needs [7]. Presently, CHCs provide primary and preventative care services to over 22 million Americans in MU communities (NACHC, 2014). Disproportionately poor, uninsured, or publicly insured patients utilize CHCs to eliminate many of the healthcare access barriers confronted by working Americans [8-13]. In fact, CHCs have proven to be a cost-effective entity for helping the MU overcome barriers to healthcare access by becoming a routine source of quality, accessible healthcare (NACHC, 2014).

Community health centers have traditionally served rural communities and communities with a higher prevalence of chronic illness. Community health centers have improved access to high quality healthcare for members of rural communities. Community health centers typically accept new patients, offer services during evenings and weekends, and tailor the delivery of healthcare services to meet the needs of diverse communities. The unique and comprehensive model of care offered by CHCs expands the traditional scope of primary care to provide a full range of preventative healthcare services. These healthcare services typically include dental, vision, mental health, and pharmacy services. Access to a wide range of healthcare services improves healthcare access. In turn, this decreases costs associated with providing primary care services in tentative care settings. Research has proven that CHCs reduce emergency department utilization among populations that historically experience challenges in access to care services [8-13].

Implementation of the ACA is dramatically increasing the number of CHCs providing healthcare for the MU. Community health centers' burden of caring for an increased number of patients, in addition to decreased amounts of federal funding and grants, and decreased reimbursements threatens $\mathrm{CHCs}^{\prime}$ ability to provide comprehensive, quality, accessible healthcare. Lack of adequate resources, limited staffing, and small facilities further limits many CHCs' ability to offer the MU a large variety of healthcare services. Although the majority of CHCs are equipped to provide the MU basic preventative care services, few CHCs have specialists on staff to deliver secondary or specialty care services. Approximately $25 \%$ of patients who visit CHCs for primary care services are diagnosed with an illness or condition that requires a referral to a healthcare provider who provides specialty care. The majority of CHCs experience difficulty in obtaining off-site specialty care services, particularly for their uninsured patients [14,12]. In fact, many CHCs in Northwest Louisiana offer limited healthcare services and struggle to find specialty care services for the $22 \%$ of Caddo parish residents who are uninsured $[15,16]$.

In summary, limited research exists which has investigated the process and outcomes of CHC coordination of MU access and utilization of specialty care services. Prior to implementation of the ACA, the focus of healthcare utilization research was on expansion of primary care access to meet the needs of the medically underserved. Six years since the enactment of the ACA, the focus has shifted from not only delivery of primary care services but also the coordinated delivery of primary and specialty care services. The coordinated delivery of primary and specialty care services ensures patients receive coordinated care within and 
across all healthcare organizations, settings, and levels of care [17].The goal of coordinated care delivery is to make appropriate healthcare referrals that meet the six aims of quality healthcare: (a) safe, (b) effective, (c) patient-centered, (d) timely, (e) efficient, and (f) equitable (Institute of Medicine (IOM), 2001). To provide coordinated healthcare delivery, medical specialists, community service agencies, hospital and emergency facilities must interact. Elements of successful collaboration which will lead to coordinated delivery of healthcare include: (a) assuming accountability, (b) providing patient support, (c) building relationships and agreements among providers (including community agencies) that lead to shared expectations for communication and care; and (d) developing connectivity via electronic or other information pathways that encourage timely and effective information flow between providers (including community agencies) (Improving Chronic Illness Care, 2016). This scholarly project will evaluate a local CHC's MU patients' access to and utilization of specialty healthcare services.

\section{Theoretical frame work}

Conceptual frameworks systematically organize the major concepts of a clinical practice change and aid in interpretation and understanding of the practice change [18]. In an effort to reduce healthcare disparities, the overall goal of the scholarly project was to implement a clinical practice change which would improve specialty care access to the medically underserved. This scholarly project was predicated on Donabedian's Model (1980). Concepts were derived from Aday and Anderson (1974) and applied to Donabedian's (1980) Structures, Processes, and Outcomes (Appendix A).

Structure in Donabedian's Model referred to the attributes of the settings in which providers deliver healthcare. Using Donabedian's Model to measure the quality of emergency care in resource-limited settings, Aaronson, Marsh, Guha, Schuur, and Rouhani [19] defined structure as human, physical, and financial resources available to provide healthcare. The structure in the DNP scholarly project included services and resources particular to the organization, professionals, and the community. Specifically, structure is the DNP student's scholarly project inclusive of the CHC and the DNP student as a professional resource; both facilitated the patient's navigation through the referral process. According to Donabedian (1988), the process of care denotes what is actually done to the patient to achieve the healthcare goals. In essence, process is synonymous with the delivery of healthcare services that were designed to achieve specific patient health outcomes. To meet these outcomes, efficient processes are necessary. Process within this scholarly project are the specific actions taken by the healthcare provider to ensure patients gain access and utilize specialty care services. One process in the scholarly project was the development and utilization of a DNP developed patient referral form. Van Driel, De Sutter, Christianens \& DeMaseneer [20] defined health outcomes as the direct result of a patient's health status as a consequence of access or contact with the health care system. Andersen and colleagues focused on utilization as a key indicator of access [21].
The desired health outcomes in this scholarly project were access and utilization of specialty care services. A modified version of Donabedian's Model guided this DNP scholarly project, and implementation of a clinical practice change. The overall intent of the scholarly project was to improve MU patients' access and utilization of specialty care services. Through the application of Donabedian's Model to the project, healthcare access and utilization of specialty care services is attainable with the appropriate structure and process. The model asserts that with adequate structure and efficient processes, the DNP student can improve MU patients' access and utilization of specialty care services, or the desired healthcare delivery outcomes (Figure 1).

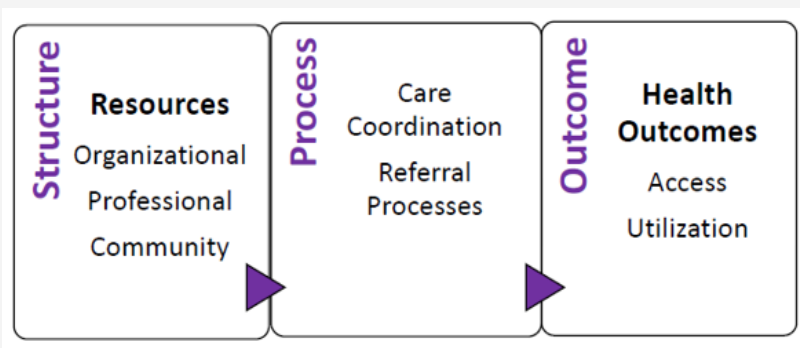

Figure 1: Modified Donabedian Structure, Process, Outcomes Model.

\section{Statement of the problem}

The problem statement in a quality improvement project clearly and succinctly explains to the reader the nature of the clinical problem that will be affected by implementation of the clinical practice change [22]. The primary problem identified by this DNP student when investigating the lack of patient access and utilization of specialty care services was the lack of efficient, systematic structure/process which coordinated the delivery of the needed specialty care services. Although the goal of the ACA was to improve healthcare coverage primarily through the expansion of Medicaid, Americans soon discovered that healthcare coverage does not equate to increased healthcare access and utilization [3,11,2325]. For example, many states, including Louisiana have assisted in the MU's enrollment in the ACA. However, access and utilization of specialty care services even after enrollment remains elusive. The limited number of healthcare providers accepting Medicaid due to low reimbursement and administrative burdens [26] as well as economic, cultural, and geographic barriers to healthcare access (HRSA, US DHHS, 2014) continue to limit the MU's access and utilization to specialty care services. Compounding these barriers to healthcare access, particularly access to specialty care services, are hospital privatizations. For example, in Northwest Louisiana, a single medical school partner hospital which historically served as the safety net for local MU needing specialty care services, was recently privatized. Community health centers, which provide primary care and preventative screening within the Northwest Louisiana community, traditionally referred patients to the medical school partner hospital when specialty care services were needed. After the hospital was privatized, many CHCs had increased difficulty obtaining specialty care services for their MU patients. 
The lack of accessible specialty care services for the MU threatens the delivery of coordinated, quality, equitable, costefficient healthcare. The lack of accessible healthcare, especially specialty care services, also leads to utilization of more expensive non-curative healthcare services such as those provided in local emergency departments (ED). The misuse of ED services undermines the benefits of the safety net services offered at CHCs and adversely impacts the state's economic viability. Individuals and families with unmet healthcare needs rely heavily upon local emergency departments [27]. The Louisiana Hospital Association (LHA) (2014) supports this claim by reporting that $80 \%$ of Louisiana hospitals have seen an increase in ED visits for the uninsured from 2013 to 2014. Medically underserved patients enrolled in the ACA coverage remain burdened with economic, cultural, and geographic barriers to specialty care access. The lack of affordable specialty care services compounded with limited specialty care providers seeing MU patients, and the privatization of Louisiana hospitals has led to MU patients seeking specialty care services through EDs, even when the MU patient receives a referral to specialty care services at a community health center.

\section{Clinical questions}

At the onset of the DNP scholarly project, the clinical question was: Is there a way to improve specialty care access for medically underserved patients receiving primary care at community healthcare centers in Northwest Louisiana? After a thorough review of literature to discover a clinical practice change that would improve specialty care access, the DNP student developed a patient referral form (PRF) to assess the MU patients' access and utilization of specialty care services (Appendix A). Once the PRF was implemented at a CHC in Northwest Louisiana, the DNP student realized that MU patients who were referred for specialty care services were receiving appointments, or gaining access to specialty care services, but they were not utilizing the specialty care services. At this point in the scholarly project, the clinical question changed to the following clinical questions:

I. Was there a difference in MU patients' access to specialty care services after implementing a clinical practice change, utilization of a DNP student developed patient referral form?

II. Was there a difference in MU patients' utilization of specialty care services after implementing a clinical practice change, utilization of a DNP student developed patient referral form?

III. What were causes of MU patients not utilizing the prescribed specialty care services?

\section{Purpose of the project}

The purpose of the DNP scholarly project was to implement a clinical practice change, use of a DNP student developed patient referral form (PRF), and evaluate MU patients' access to and utilization of specialty care services. The objectives of the scholarly project were: (a) to implement a DNP student developed PRF and evaluate MU patients' access to and utilization of specialty care services in an urban $\mathrm{CHC}$, and (b) to identify barriers to patients utilizing prescribed specialty care services.

\section{Significance}

Needs assessment: In 2013, a community needs assessment was conducted by the largest healthcare system in the Northwest Louisiana. The assessment identified limited access to specialty care as a priority community health need in Northwest Louisiana. Other identified community healthcare system weaknesses included fragmented care, lack of consumer awareness, and inappropriate use of available healthcare resources (Community Hospital Consulting (CHC) \& Willis Knighton Health System (WKHS), 2013).

To specifically assess the need for the proposed scholarly project within a local $\mathrm{CHC}$, a survey of the CHC's administrators and volunteer healthcare providers was conducted by the DNP student. Six out of seven surveys (86\%) were returned. The survey revealed that $100 \%(\mathrm{~N}=6)$ of the respondents experienced difficulty in obtaining specialty care services for MU patients in the community health center. The CHC's two most commonly needed specialty care services were gastroenterology and gynecology. The needs assessments of a large healthcare system and the DNP student recognized the need to evaluate processes and structures to improve MU patients' access to and utilization of specialty care services (CHC \& WKHS, 2013).

\section{Definition of terms}

The first step to implementation of a successful practice change is to establish clear definitions of the projects' major concepts and variables [22]. The following concepts were defined for this scholarly project: Medically underserved, specialty care services referral, specialty care access, and specialty care utilization.

\section{Medically underserved (MU):}

A. Conceptual definition: Within this project, the medically underserved include the patients who experience economic, cultural or linguistic barriers to healthcare and receive primary care services at a local community health center. Due to these barriers, the MU require support, guidance, and navigation through the specialty care referral process in order to achieve the desired healthcare outcomes.

B. Operational definition: The medically underserved is operationally defined as uninsured patients who have annual incomes $250 \%$ below the federal poverty level and who receive primary care services at a local CHC in Northwest Louisiana.

\section{Specialty care services referral}

\section{A. Conceptual definition}

Within this project, specialty care services are the structure necessary to attain the desired healthcare outcomes of specialty care access and utilization.

B. Operational definition

A referral occurs when a patient requires additional, specialized care by a medical consultant or community agency [17].Specialty care services are healthcare services that extend beyond the scope of primary and preventative care services and are delivered by a healthcare provider that has received advanced education and training in a specialty that focuses on certain parts of the body, 
periods of life, or specific disease processes (Medicare. gov - The Official US Government Site for Medicare, n. d; US Department of Veterans Affairs, 2015). In this scholarly project, specialty care services are listed under the second section of the PRF labeled Referral and include one or more of the following specialties: breast, cardiology, dermatology, endocrine, gastroenterology, gynecology, ophthalmology, orthopedics, podiatry, pulmonary, radiology, surgical services, and other.

\section{Specialty care access}

\section{A. Conceptual definition}

Specialty care access is defined as the MU patients having an opportunity to utilize specialty care services which they were referred. Medically underserved patients having specialty care access is one of the desired outcomes of the DNP student located in the CHC (structure) using the PRF (process).

\section{B. Operational definition}

For the purpose of the DNP scholarly project, specialty care access is defined as patients receiving appointments for specific specialty care services as indicated under the second section labeled Appointment Received on the Patient Referral Form. An increase in the number of MU patients receiving specialty care access was determined by an increase in the proportion of MU patients who received appointments.

\section{Specialty care utilization}

\section{A. Conceptual definition}

Though often used interchangeably, healthcare access is not synonymous with, nor does it guarantee, healthcare utilization. Access to healthcare must be secured before utilization can occur. Strongly dependent on patient compliance and/or adequate patient navigation, healthcare utilization is defined as the MU's actual use of the specialty care service. Specialty care utilization is the second desired outcome within this scholarly project. The outcome of specialty care utilization is dependent on the DNP student located in the CHC (structure) using the PRF (process).

\section{B. Operational definition}

Specialty care utilization is defined as patients receiving access and attending with specialty care providers. Specialty care utilization is indicated by the checkbox located in the third section labeled Appointment Follow Up of the Patient Referral Form. An increase in the number of MU patients receiving specialty care utilization was determined by an increase in the proportion of MU patients who attended appointments received.

\section{Project assumptions and limitations}

Assumptions: Assumptions are embedded and unrecognized truths in thinking and behavior [22]. This scholarly project was based on the following assumptions:

a. Specialty care services for the MU are not easily obtainable.

b. If specialty care access is granted, MU patients will utilize the service. c. A seamless, coordinated process for MU patient referrals and navigation will improve specialty care access.

d. Access and utilization of specialty care services will improve healthcare outcomes of the MU population.

Limitations: Limitations are project restrictions that have the potential to decrease the generalizability of the outcomes. Ideally, limitations are identified before the project is conducted to minimize their impact [22].

Limitations of this scholarly project were:

I. Long-term evaluation of outcomes was limited due to the project's time constraints.

II. Use of a small convenience sample of charts reviewed from a single $\mathrm{CHC}$ in Northwest Louisiana yielded findings that limit generalizability to a greater population.

III. The CHC's staff and providers' knowledge of the project being conducted on the access to specialty care services increases the possibility of the Hawthorne effect occurring which could threaten the validity of the project outcomes [22].

\section{Summary}

This chapter provided the reader with an overview of healthcare access for the MU including the social and economic barriers associated with healthcare access. An overview of the purpose, rationale, and impact of the project was presented. The project's framework was introduced. After defining the relevant terms, the DNP scholarly project's limitations and assumptions were discussed. Chapter two will provide the reader with a synthesis of evidence pertaining to the clinical problem and describe how the specific clinical practice change was chosen.

\section{Synthesis of Evidence}

Chapter one provided an overview of the clinical problem and the scholarly project. The scholarly project's purpose and significance were also discussed. The purpose of this DNP scholarly project was to implement a clinical practice change that improved medically underserved (MU) patients' accesses to and utilization of specialty care services. Chapter one also described how Donabedian's Model provided the structure to conduct the clinical practice change. Additionally, the project's terms were conceptually and operationally defined and the limitations and assumptions were presented. Chapter two will present a synthesis of evidence that supported implementation of a clinical practice change, or implementation of the patient referral form to improve MU patients' access and utilization of specialty care services.

Literature reviews assist DNP students in the identification of evidence supported practice changes to correct the gap between the current state and the desired state of the phenomenon of interest [18]. Multiple literature searches were conducted in CINAHL and Medline databases using the following keywords and phrases: medically underserved (MU), healthcare access, specialty care access, community health centers (CHCs), and care coordination. Keywords were utilized either singly or in combination to reflect the purpose of the DNP scholarly project. The review of literature will 
provide the reader with a thorough review of research conducted between 2000 and 2016, regarding MU patients' specialty care access and utilization. The literature review will provide a logical linkage between the identified clinical problem and the DNP student's chosen practice change. The literature review will provide evidence supporting the student's clinical practice change decision.

\section{Medically underserved}

In light of recent healthcare reforms, much of the research pertaining to MU populations has focused on the identification and elimination of healthcare access barriers. Lack of insurance coverage and healthcare providers are commonly identified barriers of medically underserved communities attempting to access healthcare services. The goal of the Affordable Care Act (ACA) was to improve healthcare access through the expansion of insurance coverage. Despite the nation's timely attempt to find solutions to improve healthcare access through enactment of the ACA, access to comprehensive healthcare remains elusive [12,28].

Medically underserved populations share one important indicator; unmet healthcare needs. Extensive research support the premise that being uninsured significantly correlates to unmet healthcare needs. In 2010, approximately 20\% of Louisiana's Caddo and Bossier Parish residents were uninsured. The Behavioral Risk Factor Surveillance System (BRFSS) identified 14.6\% of respondents in Bossier Parish and 18.1\% of respondents in Caddo Parish could not afford any type of healthcare coverage (University of Wisconsin Population Health Institute, 2015). The medically underserved are typically racial and ethnic minorities, uninsured, working poor, and reside in rural areas (NACHC, 2014). Thus, when attempting to access and utilize healthcare, the MU are challenged by social, cultural, and linguistic barriers (HRSA, US DHHS, 2014). Additionally, often falling through the cracks of the healthcare system, MU are day laborers who cannot afford to miss work opportunities and therefore do not see a healthcare provider unless they are acutely ill. Many of the MU also lack reliable transportation that further inhibits healthcare access [29]. In summary, a plethora of evidence supports the premise that MU patients experience difficulty in obtaining needed healthcare services and are at increased risk for poor healthcare outcomes and increased mortality due to work constraints as well as social, cultural, linguistic, and transportation barriers [7,38,30,31].

\section{Specialty care access}

While there is overwhelming evidence of the ACA improving the MU population's access to primary care, limited data exists which evaluates the provision of healthcare access beyond primary care services. Data from the 2012 Medical Expenditure Panel Survey (MEPS) revealed that approximately $60 \%$ of the US civilian noninstitutionalized adult population have multiple chronic conditions which require specialty care services. Further, uninsured persons reported less access to specialty care services than adults who had private or public health insurance coverage. Ethnic minorities also reported less access to specialty care services [32]. Access to specialty care is also lacking in rural [33-35]. In caring for the MU population, CHCs report greater difficulty obtaining access to off-site specialty services, including referrals and diagnostic testing $[12,14,27,36]$. The many challenges CHCs face in obtaining specialty care for their patients is well documented. However, research evidence supporting well-structured safety net programs effectiveness in improving MU's access to specialty care services is scarce.

\section{Care coordination}

To explore how CHCs across the United States (US) provide patients access to specialty care, Neuhausen et al [12]. interviewed directors of twenty CHCs across the country. Data analysis of the CHC directors' responses led to the identification of six models of how CHCs access specialty care. The most prevalent method was coined the Tin Cup Model. Reported as the least efficient way to provide specialty care access, the Tin Cup Model relies on personal relationships to solicit care from an informal network of specialists. The most efficient model for obtaining specialty care access was the Integrated System Model. The use of the Integrated System Model improved communication, increased coordination of care, and provided the patient with seamless care transition from primary to specialty care. The remaining four models ranked somewhere between the Tin Cup and Integrated System Models on a five-point scale which evaluated efficiency and satisfaction with specialty care referral [12].

Challenges to obtaining specialty care services for CHCs are compounded by the complexity of patients' illnesses and the diversity of patients' languages and cultures. These challenges cause specialty care coordination to be especially difficult [17]. To promote effective specialty care coordination, Taylor et al. [37]. recommended community collaboration and appropriate referral practices. Westminister Medical Clinic in Colorado utilized an organized, systematic referral tracking system that strongly encouraged the collaboration of specialists. The clinic also developed agreements with good neighbors that consisted of a dozen specialty groups. In order to navigate the clinic's referrals, each specialty was periodically evaluated to see how well they provided (a) access, (b) care transitions, (c) care management, and (d) communication with patients [37]. The main reason the good neighbor specialists continued to collaborate in this endeavor was the efficient manner in which the referral was processed for the scheduled specialty care appointment. Patients presented to their specialty care appointment with a full patient history, results of laboratory and imaging studies, documented reasons for referral, and all other necessary and pertinent information that made the delivery of specialty care efficient, enabling the specialists to provide quality healthcare service [37]. Nurse-Community health advocates were used to bridge health programs and the community. This strategy was effective for promoting Latino immigrant families' access to necessary healthcare services [38].

Evidence has shown that some communities are strategically organizing to better coordinate and integrate healthcare services to improve the uninsured healthcare accessibility of care. Project Access of Buncombe County pioneered a communitywide approach to the organization and facilitation of volunteer healthcare services [39]. The model established referral networks that enlisted specialists who agreed to see patients at no or minimal 
cost. Either patient navigators or network coordinators completed the necessary paperwork, scheduled the patients, and arranged for transportation and translation as necessary [30,34,39]. Research has determined that similar collaborative efforts have proven to decrease emergency room visits and inpatient hospital days among participants of these organized referral networks [25,40,41].

Effective care coordination of specialty care referrals is dependent on the CHC's awareness of the MU's specialty care needs, barriers to obtaining specialty care referrals, and the CHC's ability to navigate the MU through the referral process. San Francisco General Hospital and Trauma Center (SFGH) serves as a teaching hospital for the University of California. The hospital also serves as the hub of the county's safety net healthcare delivery system which includes thirty-five CHCs, clinics, and affiliated partners. Previous to SFGH refining its referral process, the average wait time for a gastroenterology appointment was eleven months. Referrals were paper-based, faxed or hand-delivered and often were never received, resulting in the patient not having an appointment scheduled. Countless hours were spent on the phone with clinic staff attempting to advocate for the patients and obtain a specialist appointment. To refine the referal process and improve specialty care access, an electronic referral management system was developed to track referrals for improved accountability. Subsequent to the referral process refinement, the average wait time for a gastroenterology appointment dropped to an average of less than two months [17,42]. A referral tracking system records basic patient and appointment information which aids in the development of strategies which evaluates whether key milestones, such as appointment made and appointment received, are achieved [17].

The purpose of the DNP scholarly project was to implement a clinical practice change that evaluated MU patients' accesses to and utilization of specialty care services. The DNP student developed a PRF, similar to the interventions described in this review of the literature, to evaluate MU patients' access to and utilization of specialty care services in an urban $\mathrm{CHC}$ and to identify barriers to patients utilizing the specialty care services. As demonstrated in the review of literature, adequate tracking is necessary to conduct any meaningful study of specialty care access available to the MU seen at the local community health center. Although an electronic tracking referral system would have been the most evidence supported method to improve access and utilization, the electronic system was not feasible because the CHC utilizes paper charting rather than electronic documentation.

\section{Summary}

Chapter two described a review of all available studies retrieved from MEDLINE and CINAHL databases from 2000 to 2016 using the key words: barriers to healthcare access, barriers to healthcare utilization and specifically, the lack of specialty care access for MU populations. In light of the ACA, the majority of available research found in this review of literature addressed the expansion of insurance coverage as a means to increase access. Chapter two also presented research which described the $\mathrm{CHCs}^{\prime}$ role in providing healthcare to the medically underserved. Few studies could be found which discussed solutions to providing access to specialty care services in MU communities. Even less evidence was available that supported the effectiveness of well-structured safety net programs in the improvement of MU's access to specialty care services. The DNP student utilized the review of literature to make a decision on the best practice change to evaluate in an urban CHC MU patients' barriers to access and utilization of specialty care services. With the fluidity of healthcare coverage, difficulty in obtaining an accurate measurement of healthcare access is likely a contributing factor to this evidence gap. Chapter three will describe the project's design, population sample, and setting. Ethical considerations, data collection, and data analysis will also be discussed in chapter three. Chapter three will conclude with a Strengths, Weaknesses, Opportunities, and Threats.

\section{Methodology}

Chapter two discussed the literature review that guided the DNP student in determining the clinical practice change most supported by research evidence to improve MU's access to and utilization of specialty care services. Chapter three will describe details of the project's design, setting, and sampling methods. Additionally, ethical considerations, data collection methods, and data analysis are presented. Finally, the resources required to develop, implement, analyze, and evaluate the proposed project will be discussed.

\section{Project design}

A quality improvement project design was utilized to evaluate an urban community health center's specialty care referral process before and after the implementation of a DNP student developed patient referral form (PRF). The DNP student analyzed data collected from medically underserved (MU) patients' charts to evaluate differences in MU patients' access to and utilization of specialty care services after implementing a clinical practice change, a DNP student developed patient referral form. Further, the DNP student evaluated why MU patients stated they did not utilize prescribed specialty care services.

\section{Setting and sample}

The project was implemented at a Northwest Louisiana community health center. The community health center (CHC) is a private, charitable, not-for-profit health clinic that collaborates with a local nursing school, a local medical school, and the community to provide free primary healthcare to the medically underserved. In addition to primary care services, the CHC provides laboratory testing, Sexually Transmitted Infection (STI) testing, and Human Immunodeficiency Virus (HIV) testing. Volunteer healthcare providers from medical and nursing schools deliver the primary care services in the CHC's diabetic, respiratory, cardiac, HIV, women's and geriatric clinics. The $\mathrm{CHC}$ provides primary care to the medically underserved patients within the community. The MU patients consist of working, poor, minority groups. The CHC's patients have chronic health conditions, such as hypertension and diabetes, and struggle with healthcare access and affordability.

The target population for the scholarly project included MU patients who were referred for specialty care services by the CHC healthcare providers. The project sample was generated via a 
convenience sampling method. All charts of MU patients receiving specialty care services referrals during a three-month time period before and after the clinical practice change were reviewed. The pre-practice change sample included all charts of CHC patients referred by a CHC healthcare provider for specialty care services between September 1, 2015 and December 1,2015. Once the quality improvement project was initiated, the DNP student gathered data from the charts of all CHC patients who were referred for specialty care services by the CHC healthcare providers between February 1, 2016 and May 1, 2016.

The project's inclusion criteria were: (a) charts of patients who needed specialty care services; (b) charts of patients referred by the CHC healthcare providers within the specified time-period; and, (c) charts of patients who were established CHC patients at the time of the specialty care referral. To be a patient receiving care at the CHC, and thus having a chart available for review, the participants had to meet the CHC's eligibility criteria, which included being uninsured and having an annual income below $250 \%$ of the Federal Poverty Level (FPL).

\section{Ethical considerations}

Prior to the initiation of the scholarly project, approval from the CHC and Northwestern State University Institutional Review Board (IRB) was obtained. The project received an exemption from review status in compliance with the procedures governing protection of human subjects (Appendix B). The socioeconomic disadvantages of the CHC population leads them to be considered vulnerable. The scholarly project was aimed at improving specialty care access to this patient population. Data were collected primarily from patients' clinical chart. No charts of children under 18, charts of pregnant women, fetuses, prisoners, or those with mental impairment were used. Since the data were primarily collected via chart reviews, a written consent form was not utilized. If the DNP student was unable to determine if patients received or attended an appointment via chart review, patients were contacted for a brief phone interview by the investigator or staff.

Measures to protect the confidentiality of all patient information were instituted throughout the scholarly project. Demographic and patient care data were collected and transcribed onto the PRF using patient identification numbers generated from the CHC's database. No names or personal identifiers were used. Patient identification numbers were used instead of patients' names on patient referral forms. Patient referral forms containing retrospective data were kept confidential and secure by remaining locked in the DNP student's office for the duration of the project. Patient referral forms from the prospective arm of the project were kept with the patient's clinic record. All data were secured and stored in the DNP student's office and computer which was password protected. After five years, all PRFs will be shredded and digital data files will be deleted.

\section{Data collection}

Quality improvement project data were collected at the CHC and transcribed on the DNP student developed patient referral form (PRF). The form was divided into four sections that included: demographics, referral, appointment follow up, and additional information. The demographic data included: age, gender, race, language, employment, insurance, and housing status. Specific referral information including (a) date of referral, (b) referring provider, (c) specialty type, and (d) reason for referral, were collected from the referral section of the patient referral form. The referral section of the PRF is subdivided into a section which collected data from patients who did not receive an appointment and from patients who did not attend the appointment. A follow up section asked the reasons appointments were not attended: (a) financial barriers, (b) transportation or geographic barriers, (c) work or other time commitments, (d) language or educational barrier, and (e) other. The final section of the PRF contained a blank space which allowed for the collection of additional reasons for patients not attending appointments.

At the beginning of the scholarly project, the DNP student reviewed the charts of patients who were referred for specialty care services from September 1, 2015 to December 1, 2015. Data were collected by reviewing charts and collecting and populating data into the patient referral form. The PRF was used to ascertain the specialty service needed and the time specialty services were accessed and utilized. If the DNP student was unable to determine the outcome of the referral based on the chart review, telephone interviews were conducted by the DNP student or the CHC staff in conjunction with the clinic translator if necessary. These unstructured phone interviews were also used to ascertain reasons why MU patients did not utilize specialty care services. The MU patients' answers were then placed into the one of the five preestablished categories. The fifth and other category was selected if the MU patients' reasons for not utilizing the prescribed specialty care services did not fit into the any of the four categories.

In addition to retrospective data collection, the patient referral form was the clinical practice change that was implemented on February 1, 2016. Prior to the DNP student-initiated intervention, the MU patients were referred for specialty care services through the CHC's routine referral protocol. The scholarly project simply supplemented the standard practice protocol for specialty care services at the CHC. Prior to the prospective arm of the project, the DNP student met with the CHC staff to provide an overview of the project. The patient referral form was reviewed with the staff. The staff were instructed to populate data onto the PRF at the time of referral. The patient referral form was implemented for patients who were referred to specialty care services by the CHC healthcare providers from February 1, 2016 to May 1, 2016. The PRF was included in the clinic record along with the routine referral form which continued to be utilized by the staff during the prospective arm of the project. Follow up for the prospective group continued until July 1, 2016. At that time, if the DNP student was unable to ascertain access and utilization of the specialty care service, attempts were made to contact the patient. Copies of the PRFs containing the prospective data were organized in a binder and locked in the DNP student's office to maintain confidentiality.

\section{Data analysis}

The outcome of interest was the number of MU patients who accessed and utilized specialty care services. The clinical practice 
change was implementation of the Patient Referral Form. Data analysis were performed using IBM's Statistical Package for the Social Sciences (SPSS) and Statistical Analysis System (SAS) Version 9.4. The questions guiding the scholarly project were:

a. Was there a difference in MU patients' access to specialty care services after implementing a clinical practice change, utilization of a DNP student developed patient referral form?

b. Was there a difference in MU patients' utilization of specialty care services after implementing a clinical practice change, utilization of a DNP student developed patient referral form?

c. What were causes of MU patients not utilizing the prescribed specialty care services?

To answer questions one and two, nominal level data were collected, and a chi-square test of independence was calculated to assess for differences in the proportion of patients who obtained specialty care access and utilization after the clinical practice change of the PRF implementation. To answer question three, descriptive statistics were used to analyze the frequency of responses to each of the pre-established categories. Responses that did not fit into the four pre-established categories were analyzed via content-theme analysis.

\section{SWOT assessment}

The Strengths, Weaknesses, Opportunities, and Threats (SWOT) framework was a useful tool for the DNP student in project planning. The application of the SWOT model assisted the DNP student in the realization of potential threats secondary to acknowledged weaknesses. Through minimizing weaknesses and recognizing the project's strengths, threats can be mitigated and opportunities for success can be realized [2].

The success and sustainability of the scholarly project was entirely dependent upon the support of the stakeholders. The weakness of any collaborative endeavor is the potential for the lack of collaboration and support. To be successful, the scholarly project required the multilevel support of the healthcare providers, organizations, and staff. Barriers to participation and support of the program included issues surrounding the time and effort of the volunteers and staff. For example, providers and staff could be concerned about patient compliance and the potential interruption to the workflow of the daily clinic. To coordinate and potentially expand the availability of specialty services, financial support will be necessary, likely requiring the issuance of grants and philanthropic funding (Health Policy Research Northwest, 2010).

The scholarly project provided an organized method for the assessment and tracking of specialty care referrals. Opportunities afforded by the project include the expansion of healthcare accessibility and quality. The purpose of the project was also the project's greatest strength, which was to increase MU's access to specialty care services by improving care coordination. The timing of the project was opportune and undoubtedly pertinent for the community, particularly considering the current fluidity of healthcare coverage. Local not-for-profit health systems have a large service footprint in the community and stand to benefit from the potential cost savings of the scholarly project. The project holds the potential to positively impact the community by reducing overutilization of healthcare services such as noncritical emergency department visits. The reduction of the overuse and abuse of healthcare services can have a positive impact on the overall healthcare system. Finally, the project can and will create partnerships and alliances within the community that contribute to a healthier community.

\section{Summary}

This chapter provided the reader with a description and design of the project. The setting, sampling methods, and participants were presented. Ethical considerations were addressed. Data collection methods and analysis were discussed. Strengths, weaknesses, opportunities, and threats of the project were also presented. Chapter four will present the reader with an overview of the project's findings and results.

\section{Data Analysis and Results}

Chapter three described the project's design, setting, sampling methods, participants, and ethical considerations. Data collection methods and analysis were outlined. Strengths, weaknesses, opportunities, and threats of the project were also presented. Chapter four will present the results of data analysis. The chapter will first discuss analysis of demographic data and then specifically describe the results of data analysis used to answer the scholarly project's three clinical questions:

a. Is there a difference in medically underserved (MU) patients' access to specialty care services after implementing a clinical practice change, utilization of a DNP student developed patient referral form?

b. Is there a difference in MU patients' utilization of specialty care services after implementing a clinical practice change, utilization of a DNP student developed patient referral form?

c. What are causes of MU patients not utilizing the prescribed specialty care services?

To answer questions one and two, chi-square tests of independence were used to calculate differences in the proportion of patients who obtained specialty care access and utilization after the clinical practice change, or the patient referral form (PRF) was implemented. Question three was answered by calculating frequency of responses to pre-established categories, and through content-theme analysis. After answering the primary research questions, results from additional data analysis will be discussed.

\section{Description of sample}

The scholarly project's total sample $(\mathrm{N}=48)$ consisted of retrospective, or pre-intervention group charts, and prospective, or post-intervention group charts. The retrospective group $(n=24)$ included charts of patients who were referred for specialty care services from September 1, 2015 to December 1, 2015. The postintervention group $(n=24)$ included charts of patients who were referred for specialty care services from February 1, 2016 to May 
1, 2016. Demographic characteristics of both groups were similar as depicted in (Table 1).

Table 1: Demographic Characteristics.

\begin{tabular}{|c|c|c|c|}
\hline Characteristics & $\begin{array}{c}\text { Retrospective } \\
\text { Group (n= 24) } \\
\%\end{array}$ & $\begin{array}{c}\text { Prospective } \\
\text { Group (n= 24) } \\
\text { \% }\end{array}$ & $\begin{array}{c}\text { Total (N = } \\
\mathbf{4 8}) \%\end{array}$ \\
\hline \multicolumn{4}{|c|}{ Gender } \\
\hline Male & 20.8 & 4.2 & 12.5 \\
\hline Female & 79.2 & 95.8 & 87.5 \\
\hline Ethnicity & & & 37.5 \\
\hline White & 41.7 & 33.3 & 37.5 \\
\hline African & 33.3 & 41.7 & 25 \\
\hline Hisprican & 25 & 25 & 77.1 \\
\hline Language & & 75 & 22.9 \\
\hline English & 79.2 & 25 & \\
\hline Spanish Only & 20.8 & & \\
\hline
\end{tabular}

Of the total sample $(\mathrm{N}=48), 88 \%(\mathrm{n}=42)$ were females. Thirtyeight percent $(n=18)$ of the patients were White, $38 \%(n=18)$ were African American, and 25\% ( $n=12)$ were Hispanic $(n=12)$. The majority of patients $(77.1 \%, n=37)$ were English speaking but approximately $23 \%(n=11)$ of the patients only spoke Spanish (Table 1). The ages of both groups ranged from 23 to 73 years with a mean age of 50 years for the retrospective group and 51 years for the prospective group (Table 2).

Table 2: Summary statics for age.

\begin{tabular}{|c|c|c|}
\hline \multirow{4}{*}{ Retrospective Group } & Mean & 49.5 \\
\cline { 2 - 3 } & $\mathrm{N}$ & 24 \\
\cline { 2 - 3 } & Std. Deviation & 9.103 \\
\cline { 2 - 3 } & Median & 51 \\
\hline \multirow{4}{*}{ Prospective Group } & Mean & 51.21 \\
\cline { 2 - 3 } & N & 24 \\
\cline { 2 - 3 } & Std. Deviation & 10.966 \\
\cline { 2 - 3 } & Median & 53 \\
\hline \multirow{4}{*}{ Total } & Mean & 50.35 \\
\cline { 2 - 3 } & N & 48 \\
\cline { 2 - 3 } & Std. Deviation & 10.007 \\
\cline { 2 - 3 } & Median & 52 \\
\hline
\end{tabular}

Referrals in the retrospective group were most commonly made to gynecology $(29.2 \%, \mathrm{n}=7)$, gastroenterology $(20.8 \%, \mathrm{n}=5)$, breast $(12.5 \%, \mathrm{n}=3)$, and endocrinology $(12.5 \%, \mathrm{n}=3)$ specialties. Referrals in the prospective group were most commonly made to gynecology $(29.2 \%, n=7)$, gastroenterology $(20.8 \%, n=5)$, general medicine $(20.8 \%, n=5)$, and breast $(16.7 \%, n=4)$ specialties. Referrals in both groups were most commonly made to gynecology (29.2\%, $\mathrm{n}=14)$, gastroenterology $(20.8 \%, \mathrm{n}=10)$, and breast $(14.6 \%$, $\mathrm{n}=7$ ) specialties (Table 3 ).
Table 3: Area of Specialty.

\begin{tabular}{|c|c|c|c|}
\hline Specialty & $\begin{array}{c}\text { Retrospective } \\
\text { Group (n= } \\
\mathbf{2 4 ) \%}\end{array}$ & $\begin{array}{c}\text { Prospective } \\
\text { Group (n= 24) } \\
\mathbf{\%}\end{array}$ & $\begin{array}{c}\text { Total (N = } \\
\mathbf{4 8}) \mathbf{\%}\end{array}$ \\
\hline Breast & 12.5 & 16.7 & 14.6 \\
\hline Cardiology & 4.2 & 0 & 2.1 \\
\hline Endocrinology & 12.5 & 0 & 6.3 \\
\hline Gastroenterology & 20.8 & 20.8 & 20.8 \\
\hline Gynecology & 29.2 & 29.2 & 29.2 \\
\hline General Medicine & 4.2 & 20.8 & 12.5 \\
\hline Hematology & 4.2 & 0 & 2.1 \\
\hline Ophthalmology & 4.2 & 4.2 & 4.2 \\
\hline Psychiatry & 4.2 & 0 & 2.1 \\
\hline Pulmonology & 4.2 & 0 & 2.1 \\
\hline Urology & 0 & 4.2 & 2.1 \\
\hline Orthopedics & 0 & 4.2 & 2.1 \\
\hline
\end{tabular}

The most common location to which patients in both groups were referred for specialty care services was a local university hospital (UH) that houses specialty clinics $(83.3 \%, n=40)$. The community health center where the primary care services were delivered was also a location where patients received specialty care $(10.4 \%, n=5)$. Delivery of specialty care at the same location where patients received primary care services required the specialist to be on site at the $\mathrm{CHC}$ rather than being at an off-site location. Other locations where patients were sent to receive specialty care included local private hospitals and clinics $(6.3 \%, \mathrm{n}=3)$ (Table 4).

Table 4: Location of Referral.

\begin{tabular}{|c|c|c|c|}
\hline Location & $\begin{array}{c}\text { Retrospective } \\
\text { Group (n=24)\% }\end{array}$ & $\begin{array}{c}\text { Prospective } \\
\text { Group (n = 24) } \\
\text { \% }\end{array}$ & $\begin{array}{c}\text { Total (N = } \\
\text { 48) \% }\end{array}$ \\
\hline $\begin{array}{c}\text { University } \\
\text { Hospital (UH) }\end{array}$ & 95.8 & 70.8 & 83.3 \\
\hline $\begin{array}{c}\text { Martin Luther } \\
\text { King Health } \\
\text { Center (MLKHC) }\end{array}$ & 4.2 & 16.7 & 10.4 \\
\hline Other & 0 & 12.5 & 6.3 \\
\hline
\end{tabular}

\section{Presentation of findings}

Having presented a broad overview of patients whose charts were included in the retrospective and prospective groups, and a broad overview of specialties and locations patients were referred to when needing specialty care access, the results of data analysis to answer each clinical question will now be discussed. Data were analyzed using IBM's Statistical Package for the Social Sciences (SPSS) and Statistical Analysis System (SAS) Version 9.4.

\section{Clinical questions}

clinical question one: To answer clinical question one and assess for a difference in access to specialty care services after implementation of a DNP student developed patient referral form, a chi-square test of independence was performed. No statistically significant difference was found in the proportion of patients who received an appointment after the PRF was implemented 
as compared to the proportion of patients who received an appointment before the PRF was implemented $(\chi 2(1)=.000, p>$ .05) (Table 5). Thus, data analysis concluded implementation of a DNP student developed PRF did not make a statistically significant difference on MU's specialty care access.

Table 5: Access (Appointment Received) between Groups.

\begin{tabular}{|c|c|c|c|c|}
\hline \multicolumn{2}{|c|}{$\begin{array}{c}\text { Groups } \\
\text { No }\end{array}$} & \multicolumn{3}{c|}{ Appointment Received } \\
\cline { 3 - 5 } & Ces & Total & \\
\hline \multirow{3}{*}{ Retrospective Group } & 11 & 13 & 24 \\
\hline & \% within Group & 45.8 & 54.2 & 100 \\
\hline Prospective Group & Count & 11 & 13 & 24 \\
\hline \multirow{2}{*}{ Total } & \% within Group & 45.8 & 54.2 & 100 \\
\hline & Count & 22 & 26 & 48 \\
\% within Group & 45.8 & 54.2 & 100 \\
\hline
\end{tabular}

clinical question two: To answer the second clinical question and evaluate the difference in MU utilization of specialty care services after implementation of the DNP student developed patient referral form, a chi-square test of independence was performed Calculations were based solely on the MU patients who received appointments, or had access, in both the retrospective and prospective groups $(n=26)$. No significant difference was found between the proportion of patients who utilized specialty care services before or after implementation of the PRF $(\chi 2(1)=1.4182$, $\mathrm{p}=0.2337$ ) (Table 6). Thus, data analysis revealed that use of a DNP student developed PRF did not change MU patients' utilization of specialty care services to a level of statistical significance. Post-hoc power computations were performed to determine if sample size was sufficient to detect a clinically significant difference between the two groups. Post hoc power was detected to be $11 \%$ thus, indicating that the sample size was only large enough to detect a $23 \%$ difference (31\% vs. $54 \%$ ) in utilization between the groups.

Table 6: Utilization (Appointment Attended) between Groups.

\begin{tabular}{|c|c|c|c|c|}
\hline \multicolumn{2}{|c|}{ Groups } & \multicolumn{3}{c|}{ Appointment Received } \\
\cline { 5 - 5 } & No & Yes & Total & \\
\hline \multirow{2}{*}{ Retrospective Group } & Count & 9 & 4 & 13 \\
& \% within Group & 69.2 & 30.8 & 100 \\
\hline \multirow{2}{*}{ Prospective Group } & Count & 6 & 7 & 13 \\
& \% within Group & 46.2 & 53.9 & 100 \\
\hline \multirow{2}{*}{ Total } & Count & 15 & 11 & 26 \\
& \% within Group & 45.8 & 54.2 & 100 \\
\hline
\end{tabular}

Having used quantitative data analysis to answer clinical questions one and two, descriptive statistics and content-theme analysis were used to answer clinical question three.

clinical question three: The DNP student conducted a phone interview inquiring about reasons for the lack of utilization $(\mathrm{N}=15)$. Financial, language, and work or other time commitments were three categories equally cited as barriers to MU patients utilizing specialty care services $(n=2,13 \%)$. Transportation was not cited by the MU patients as a barrier to utilizing specialty care services $(\mathrm{n}=0)$ (Table 7).

Content-theme analysis allows for the recognition, identification, and development of themes and patterns from narrative data (Grove et al, 2013). Content-theme analysis was used to develop themes from the MU patients' self-reported reasons they did not utilize specialty care services that did not fit into one of the four pre-established categories. Each of these reasons were written under the other category and further explained why MU patients did not utilize the prescribed specialty care services $(n=9)$. These nine qualitative responses were then categorized into themes. Two themes emerged as reasons why MU patients did not utilize specialty care services: acquired healthcare insurance $(n=2,13 \%)$, no knowledge of appointment $(n=7,48 \%)$. Table 7 presents MU patient cited barriers for the non-utilization of specialty care when specialty care access was provided. The following are examples of MU patients' descriptions which were categorized into the acquired healthcare insurance theme:

Table 7: Barriers to Specialty Care Utilization ( $N=15)$.

\begin{tabular}{|c|c|c|}
\hline Barriers & $\mathrm{n}$ & $\%$ \\
\hline Financial (Had to pay) & 2 & 13 \\
\hline $\begin{array}{c}\text { Transportation or Geographic } \\
\text { Barriers }\end{array}$ & 0 & 0 \\
\hline Work or other time commitments & 2 & 13 \\
\hline Language or Educational Barrier & 2 & 13 \\
\hline Other: acquired healthcare insurance & 2 & 13 \\
\hline Other: No knowledge of appointment & 7 & 48 \\
\hline
\end{tabular}

Patient Prospective 24: “...received insurance and went to back to private doctor"

Patient Retrospective 5: "I have a private doctor now."

The following are examples of MU patients' descriptions which were categorized into the no knowledge of appointment theme:

Patient Retrospective 8: "I didn't know I had an appointment."

Patient Retrospective 12: “...No one called me to tell me I had an appointment"

\section{Additional data analysis}

To further explain the DNP student's clinical observations made while implementing this clinical practice change, additional data analysis were performed to evaluate specialty care access and utilization between the retrospective and prospective groups and the types of specialties to which MU patients were referred. Survival analyses were performed to estimate the time from the referral to specialty care access and utilization. Survival analysis is designed to analyze repeated measures from a given time until a certain attribute or event [22]. The time to event is a variable that represents the duration of the clinical course, where each subject has a beginning and an end point along the timeline of the entire project or study [43].

In this scholarly project, the time to event was the patient receiving an appointment (access) or attending an appointment (utilization). The time to event began with the patient's date of referral. Patients included in the retrospective group received specialty care referrals from September 1, 2015 to December 1, 2015. Patients included in the prospective group received specialty care referrals from February 1, 2016 to May 1, 2016. The end point occurred when the patient received (access) or attended (utilization) an appointment. If neither of these events occurred, 
the patients were censored from the project. Censoring translated to an indeterminate total survival time. Censored patients were those patients who did not receive (access) or attend (utilization) an appointment by February 1, 2016 for the retrospective group or by July 1, 2016 for the prospective group (Figure 2).

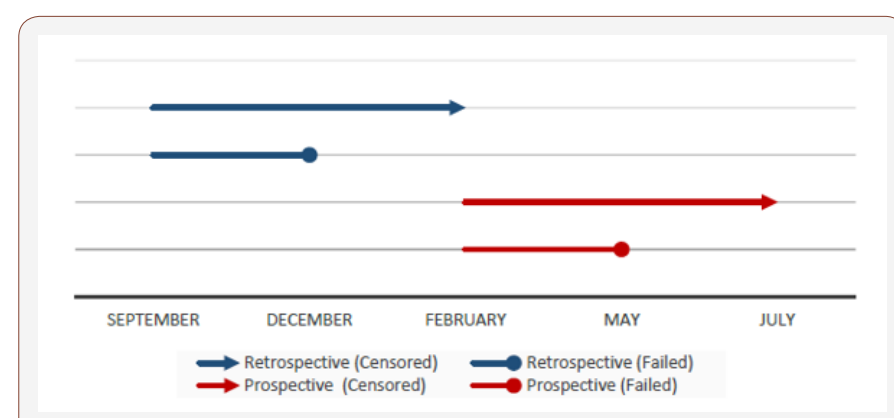

Figure 2: Survival Analysis.

\section{specialty care access}

\section{Groups}

Survival analysis was performed to estimate time to access, or appointment received, for both retrospective and prospective groups. The retrospective and prospective groups had an equal number of censored values, which represented MU patients who did not receive appointments $(n=11)$. The median survival time, or estimated time to specialty care access in both groups was approximately 15 weeks. Table 8 depicts the findings of the time to specialty care access survival analysis for both groups.

Table 8: Survival Analysis of Time to Access between Groups.

\begin{tabular}{|c|c|c|c|c|}
\hline \multirow{2}{*}{ Groups } & \multicolumn{2}{|c|}{$\begin{array}{c}\text { Appointment } \\
\text { Received }\end{array}$} & $\begin{array}{c}\text { Median } \\
\text { Survival } \\
\text { Time to } \\
\text { Appointment } \\
\text { Attended } \\
\text { (weeks) }\end{array}$ \\
\cline { 2 - 5 } & $\begin{array}{c}\text { No } \\
\text { (Censored) } \\
\mathbf{n}=\mathbf{2 2}\end{array}$ & $\begin{array}{c}\text { Yes } \\
\text { (Failed) } \\
\mathbf{n = 2 6}\end{array}$ & $\begin{array}{c}\text { Total } \\
\mathbf{N}=\mathbf{4 8}\end{array}$ \\
\hline $\begin{array}{c}\text { Retrospective } \\
\text { Group }\end{array}$ & 11 & 13 & 24 & 15 \\
\hline $\begin{array}{c}\text { Prospective } \\
\text { Group }\end{array}$ & 11 & 13 & 24 & 15 \\
\hline
\end{tabular}

Having described the time to specialty care access for both groups via survival analysis, a log rank test was then conducted to determine if a statistically significant difference was found between the retrospective and prospective groups. No statistically significantly difference was found in time to specialty care access between the retrospective and prospective groups $(\chi 2(1)=.0047$, $\mathrm{p}=0.9456$ ) (Table 9). Thus, the time it took MU patients to receive a specialty care appointment, or gain access to specialty care services, was not statistically significantly different after implementation of the DNP student developed patient referral form.

Table 9: Time to Access between Groups: Log-Rank Test.

\begin{tabular}{|c|c|c|c|}
\hline Test & Chi-Square & dF & p value \\
\hline Log-Rank & 0.00047 & 1 & 0.9456 \\
\hline
\end{tabular}

Figure 3 depicts log rank analysis of time to access on a survival analysis curve to demonstrate that the time to access in the prospective group did not statistically significantly differ from the time to access in the retrospective group.

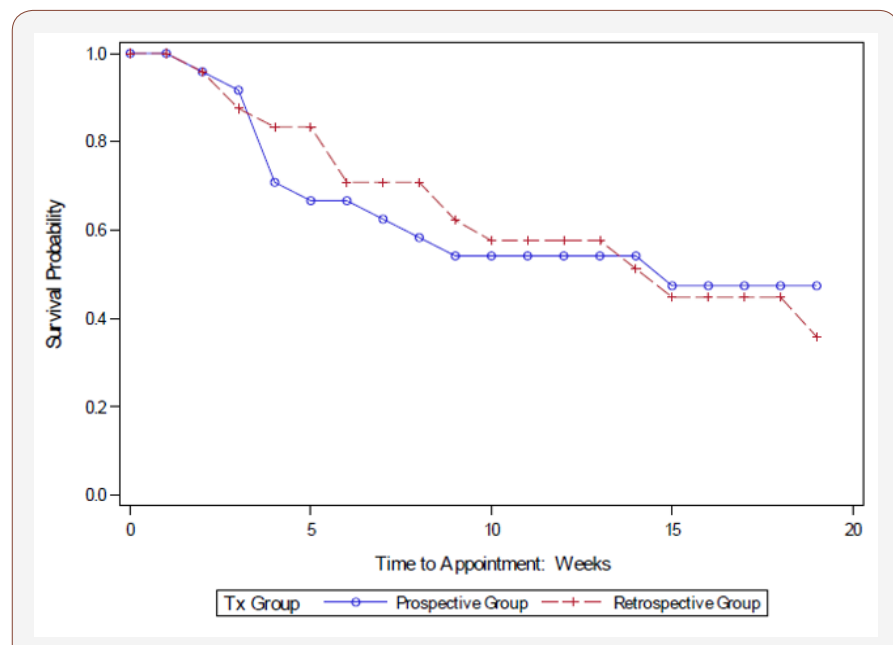

Figure 3: Survival Analysis Curve of Time to Access between Groups.

After survival analyses were performed to estimate time to specialty care access, or appointment received, for both retrospective and prospective groups, additional data analyses were performed to evaluate specialty care access by specialty.

Specialty: Gynecology $(29.2 \%, \quad n=14)$, gastroenterology (20.8\%, n=10), and breast $(14.6 \%, n=7)$ were the most common specialty care services to which MU patients were referred. A chi-square test of independence was performed to determine if there was a statistically significant difference in MU access among specialties. A statistically significant difference was found in MU access rates by specialty service $(\chi 2(3)=8.800, p=0.0321)$. All MU patients who were referred for breast services received an appointment or had access to specialty care services $(100 \%$, $\mathrm{n}=7$ ). Interestingly, MU patients who were referred for a specialty care appointment for breast care services received breast care appointments at a statistically significant higher rate than all other specialty care referrals (Table 10). Thus, MU patients who were referred for specialty breast care services received a specialty care appointment, or gained access to specialty care services, at a statistically significantly higher rate than all other specialties.

Table 10: Access by Specialty.

\begin{tabular}{|c|c|c|c|}
\hline \multirow{2}{*}{ Specialty } & \multicolumn{3}{|c|}{ Access (Appointment Received) } \\
\cline { 2 - 4 } & $\begin{array}{c}\text { Yes } \\
\mathbf{n = 2 6}\end{array}$ & $\begin{array}{c}\text { No } \\
\mathbf{n = 2 2}\end{array}$ & $\begin{array}{c}\text { Total } \\
\text { N=48 }\end{array}$ \\
\hline \multirow{2}{*}{ Breast } & 7 & 0 & 7 \\
\hline \multirow{2}{*}{ Gastroenterology } & $100 \%$ & $0 \%$ & 10 \\
\hline \multirow{2}{*}{ Gynecology } & 4 & 6 & 14 \\
\hline \multirow{2}{*}{ Other } & 5 & $60 \%$ & 17 \\
\hline
\end{tabular}

After analyzing MU patients' access to specialty care services, or appointment rates for each specialty, survival analysis was 
performed to examine time to obtain an appointment, or to gain access by specialty, after the referral has been made (Table 11). The median survival time, or estimated time to appointment, for breast specialty care services was four weeks. The median survival time for gastroenterology and gynecology specialties was greater than 19 weeks but was indeterminate because less than half of the patients received an appointment. Fifteen weeks was the median survival time of other specialties, including: cardiology, endocrinology, general medicine, hematology, ophthalmology, psychiatry, pulmonology, urology, and orthopedics (Table 11). Thus, the MU's estimated time to appointment, or specialty care access, for breast services was four weeks and shorter than all other specialties. Having described the performed data analysis to evaluate time to access, or appointment by specialty, a log rank test was conducted to determine if the difference in time to access by specialty type was statistically significant (Table 12).

Table 11: Survival Analysis of Time to Access by Specialty Specialty.

\begin{tabular}{|c|c|c|c|c|}
\hline \multirow[b]{2}{*}{ Speciality } & \multicolumn{3}{|c|}{ Appointment Attended } & \multirow{2}{*}{$\begin{array}{c}\text { Median } \\
\text { Survival } \\
\text { Time to } \\
\text { Appointment } \\
\text { (weeks) }\end{array}$} \\
\hline & $\begin{array}{c}\text { No } \\
\text { (Censored) } \\
\mathbf{n}=22\end{array}$ & $\begin{array}{c}\text { Yes } \\
\text { (Failed) } \\
\mathrm{n}=26\end{array}$ & $\begin{array}{r}\text { Total } \\
\mathrm{N}=48\end{array}$ & \\
\hline Breast & 0 & 7 & 7 & 4 \\
\hline Gastroenterology & 6 & 4 & 10 & $>19$ \\
\hline Gynecology & 9 & 5 & 14 & $>19$ \\
\hline Other & 7 & 10 & 17 & 15 \\
\hline
\end{tabular}

Table 12: Time to Access by Specialty: Log-Rank Test.

\begin{tabular}{|c|c|c|c|}
\hline Test & Chi-Square & dF & p value \\
\hline Log-Rank & 20.0523 & 3 & 0.0002 \\
\hline
\end{tabular}

Survival analysis curve of time to access by specialty indicated a statistically significantly difference between breast care and all other specialties $(\chi 2(3)=20.05, p=0.0002)$. (Table 12). Thus, time to access or appointment for MU patients referred for breast care services was statistically significantly shorter than MU patients referred to all other specialties. Figure 4 depicts these findings on a survival analysis curve.After analyzing specialty care access between the groups and by specialty, additional data analysis was performed to evaluate specialty care utilization between the retrospective and prospective groups.

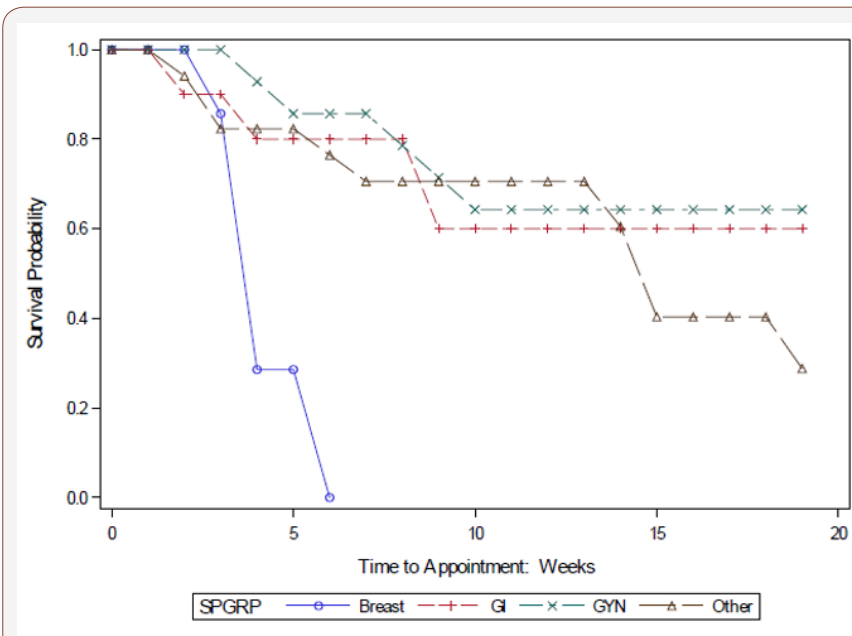

Figure 4: Survival Analysis Curve of Time to Access by Specialty. specialty care utilization: Survival analysis was performed to evaluate the time to specialty care utilization, or appointment attended, for the retrospective and prospective groups. These analyses only included the MU patients who received an appointment $(n=26)$. In the retrospective group, the median time to specialty care utilization was 15 weeks. In the prospective group, the median time to specialty care utilization was eight weeks (Table 13). After data analysis was performed to evaluate time to specialty care utilization between the retrospective and prospective groups, a log rank test was performed to determine if a statistically significant difference existed between the retrospective and prospective groups (Table 14).

Table 13: Survival Analysis of Time to Utilization between Groups.

\begin{tabular}{|c|c|c|c|c|}
\hline \multirow{2}{*}{ Groups } & \multicolumn{3}{|c|}{ Appointment Attended } & $\begin{array}{c}\text { Median } \\
\text { Survival } \\
\text { Time to } \\
\text { Appointment } \\
\text { Attended } \\
\text { (weeks) }\end{array}$ \\
\cline { 2 - 5 } & $\begin{array}{c}|c| \\
\text { No } \\
\text { (Censored) } \\
\mathbf{n = 1 5}\end{array}$ & $\begin{array}{c}\text { Yes } \\
\text { (Failed) } \\
\mathbf{n = 1 1}\end{array}$ & $\begin{array}{c}\text { Total } \\
\mathbf{N}=\mathbf{2 6}\end{array}$ \\
\hline $\begin{array}{c}\text { Retrospective } \\
\text { Group }\end{array}$ & 9 & 4 & 13 & 15 \\
\hline $\begin{array}{c}\text { Prospective } \\
\text { Group }\end{array}$ & 6 & 7 & 13 & 8 \\
\hline
\end{tabular}

The survival analysis curve of time to utilization between the retrospective and prospective groups was not statistically significant different $(\chi 2(1)=1.9238, p=0.1654)$ (Table 14), thus indicating the DNP student developed PRF did not make a statistically significant difference in the time to specialty care utilization among the MU patients who received appointments. Figure 5 depicts the survival analysis curve of time to utilization between the two groups.

Table 14: Time to Utilization between Groups: Log-Rank Test.

\begin{tabular}{|c|c|c|c|}
\hline Test & Chi-Square & dF & p value \\
\hline Log-Rank & 1.9238 & 1 & 0.1654 \\
\hline
\end{tabular}

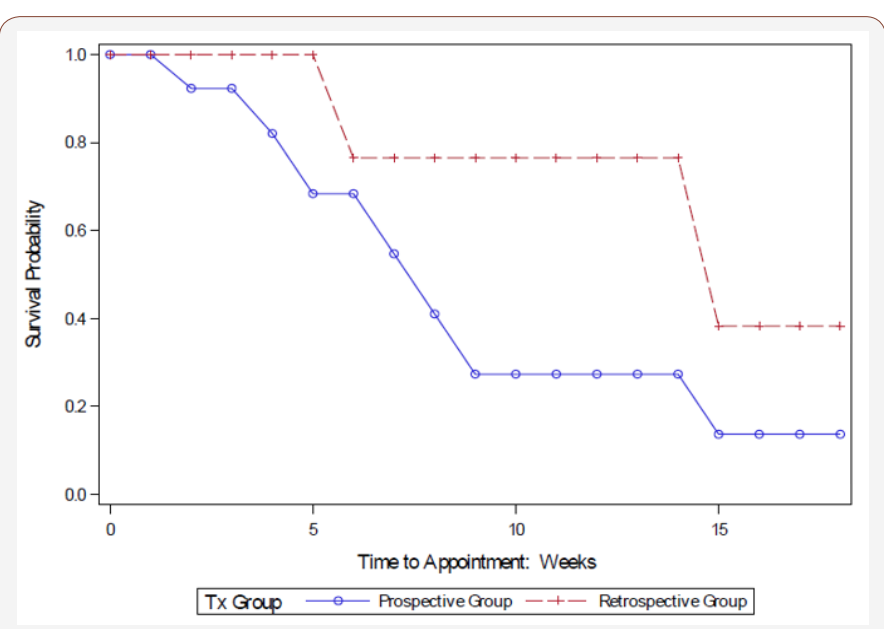

Figure 5: Survival Analysis Curve of Time to Access by Specialty.

\section{Summary}

Chapter four provided a detailed presentation of the project's findings and results. To answer questions one and two, a chi-square 
test of independence was calculated to assess for differences in the proportion of patients who obtained specialty care access and utilization after the DNP student developed PRF implementation. Descriptive and content-theme analysis were utilized to answer clinical question three. Additionally, survival analysis of time to access and utilization was presented. Overall, no statistically significant difference was found in MU patients' access to or utilization of specialty care services after implementation of a clinical practice change, or implementation of a DNP student developed patient referral form. However, a key finding of data analysis was that MU patients cited lack of awareness or knowledge of the scheduled appointment as the primary reason they did not utilize specialty care services. Chapter five will discuss the interpretations, conclusions, and recommendations of the scholarly project.

\section{Conclusions and Recommendations}

Chapter four discussed the results of data analysis to answer the three clinical questions used to evaluate the DNP student's clinical practice change, or implementation of the patient referral form (PRF). To further explain observations of the DNP student while implementing the clinical practice change, additional data analyses were performed. Based on both statistical and clinical data, the DNP student attaches meaning to the findings to render interpretations [22]. Chapter five will provide interpretations, conclusions, and applications of the project's findings. The outcomes will be summarized and applied to advanced nursing practice. Recommendations for further research will also be discussed. Interpretations and conclusions of data analyses will be presented to answer the following questions which evaluated the implementation of the clinical practice change:

a. Was there a difference in medically underserved (MU) patients' access to specialty care services after implementing a clinical practice change, utilization of a DNP student developed patient referral form?

b. Was there a difference in MU patients' utilization of specialty care services after implementing a clinical practice change, utilization of a DNP student developed patient referral form?

c. What were causes of MU patients not utilizing the prescribed specialty care services?

\section{Discussion}

specialty care access: Specialty care access was evaluated before and after implementation of the clinical practice change. The result of the data analysis indicated there was no statistically significant difference $(\chi 2(1)=.000, \mathrm{p}>.05)$ in MU patient's access to specialty care services with the implementation of the clinical practice change, utilization of a DNP student developed patient referral form. To evaluate access among the two groups, additional data analysis revealed that the median survival time for patients to receive a specialty care appointment was fifteen weeks for both the retrospective and prospective groups. Although this finding suggests that the patient referral form had no impact on specialty care access for the MU population, the PRF did improve documentation of the referral process in the prospective group.

The DNP student concluded that use of the PRF did not change the CHC's method of obtaining specialty care appointments. The local CHC relied on the Tin Cup Model to schedule appointments for specialty care services for MU patients in both the retrospective and prospective groups. One of the staff members, who scheduled many of the appointments, was a past employee of the most commonly referred to specialty facility, and many of the appointments were scheduled when this staff member contacted her previous coworkers who worked within the specialty clinic. Therefore, the Tin Cup Model proved useful in scheduling or helping patients gain access to specialty care services. Contrary to this finding, previous research has documented that the Tin Cup Model is the least reliable method to obtain specialty care services [12]. The Tin Cup Method would most likely prove to be equally inefficient over time for the CHC within the scholarly project because the Tin Cup Method is an inconsistent method of providing referrals and dependent on multiple variables which change over time.

In the evaluation of time to access by specialty, additional data analyses revealed that all MU patients who needed breast specialty care services $(n=7)$ received an appointment. The time to access of breast specialty care services for the MU population was four weeks. This was more expeditious than for any other specialty. The quick time to access was attributed to the CHC's volunteer breast specialist who sees patients on site one to two times a month at the community health center. These findings suggest that having specialty care services available at the $\mathrm{CHC}$, rather than depending on off-site referrals, improves specialty care access.

specialty care utilization: Specialty care utilization was evaluated before and after the implementation of the clinical practice change. For the MU patients receiving appointments $(n=26)$, there was an increase in utilization of the appointments after the clinical practice change, utilization of a DNP student developed patient referral form (31\% vs. 54\%). Of the total MU patients who received appointments $(n=26)$, the PRF increased specialty care utilization rates by twenty-three percent. Although the results were not statistically significant $(\chi 2(1)=1.4182, p=$ 0.2337 ), the results were clinically significant. The lack of statistical significance was attributed to the inadequate sample size of the project as evidenced by $11 \%$ post hoc power analysis. With a larger sample size, the findings would likely be statistically significant. The slight improvement in utilization was clinically significant because the PRF increased provider and staff awareness prompting follow-up of MU patients' utilization.

In evaluating the lack of utilization by MU patients who received access ( $n=15)$, several barriers were identified. Thirteen percent of the MU patients who received access but did not utilize specialty care services cited language or educational barriers as reasons for the lack of utilization $(n=2)$. Many of the MU patients needing a referral only spoke Spanish and the CHC only has one translator on staff. Due to the recent Medicaid Expansion in Louisiana, some of the MU patients received insurance coverage and went to a 
private clinic rather than continuing their care at the community health center $(n=2,13 \%)$. Referred patients cited work and other commitments $(n=2,13 \%)$ and financial barriers $(n=2,13 \%)$ as reasons for lack of utilization. Since the privatization of the local university hospital, many MU patients cannot afford the up-front fee now required for any healthcare services.

Perhaps the most significant finding in evaluating reasons for the lack of MU utilization of specialty care services was that patients were often unaware of their scheduled appointments ( $n=7,48 \%$ ). Once the referral was ordered by the provider, the staff typically faxed the form to the referred facility. The most common facility that providers referred to utilized automated phone calls to notify patients of their appointment date and time. The majority of MU patients who reported a lack of awareness of the appointment reported not receiving a phone call about the appointment. One patient admitted that they may have received the phone call but likely hung up thinking it was a sales call. Therefore, how can patients attend or utilize services if they are not aware that they have gained access?

\section{Recommendations}

Specialty care access: The findings of the scholarly project illuminated the need for improved communication between the CHC, referral sites, and patients, thus emphasizing the importance of communication and collaboration among all elements within the healthcare system. The Tin Cup Model which was utilized by the CHC was identified in the literature as the least reliable and efficient way for obtaining specialty care services. While the Tin Cup Model relies on an informal, transient network of specialists, the more efficient models integrated CHCs with local government or private healthcare systems to form a comprehensive network of specialists [12]. Evidence has shown that communities that organize to coordinate and integrate healthcare services improve healthcare accessibility [25,39-41]. Similar collaborative efforts are strongly recommended for the $\mathrm{CHC}$ to form relationships and partnerships within the community, particularly the local university hospital. This opportunistic endeavor will expand MU patients' access to specialty care services and improve the overall health of the patients and the community.

Specialty care utilization: Evidence has shown that one of the major contributors to success for collaborative referral networks is an organized, systematic referral process. The patient referral form (PRF) was implemented as a referral tracking system and served to improve provider and staff awareness. The slight improvement in utilization could be attributed to this newfound awareness and accountability which is necessary to assure that the MU are successfully navigated through the referral process to completion.

Since no single healthcare entity can bring about the changes needed in healthcare reform, accountability, or shared responsibility, should extend beyond the organization. Neuhausen et al [12]. recognized an Integrated Model System that had incorporated a single electronic medical record (EMR) system and a web-based referral platform shared among the CHCs, hospitals, and specialists. The implementation of this model improved communication, increased coordination of care, and provided the patients with seamless care transitions from primary to specialty care [12]. In this scholarly project, the CHC implementation of an EMR that communicates with the local university hospital would be ideal. If cost is a concern, the CHC should at least seek to implement a consistent, organized, and systematic method to communicate and coordinate specialty care services with the local university hospital.

Much research has focused on the identification and elimination of barriers to healthcare access and utilization. For decades, CHCs have met the diverse needs of rural communities by overcoming many of the challenges faced by the medically underserved. The provision of specialty care services on site eliminates some of the barriers to specialty care utilization identified by the MU patients. Improving MU availability and accessibility to providers who understand the culture, linguistic, transportation, and financial challenges is invaluable to a community. The provision of specialty care services also reduces the duplication of services and the fragmentation of care, particularly in the avoidance of transitions from one location to another.

Based on the project's data analyses, relationships between specialty care utilization and care coordination were identified. As recognized in the literature, care coordinators or patient navigators provide patient support and assistance in navigating through the complex healthcare system. In the scholarly project, patient navigation was improved using a translator and by the assistance of the CHC staff in scheduling referral appointments. Improving MU patients' navigation through the specialty care referral system as well as active recruitment of specialists who would provide specialty care services at the $\mathrm{CHC}$ were recognized as ways to provide a supportive referral structure that would improve patients' access and utilization of specialty care services.

\section{Framework application}

The findings of the project were applied the modified Donabedian's Structure, Processes, and Outcomes Model (Figure 1). The model asserted that specialty care access and utilization is best achieved with adequate structure and efficient processes.

In the scholarly project, there was not a difference in the proportion of MU patients who received appointments before and after the implementation of the patient referral form. However, the MU patients that received appointments were more likely to attend the appointments after the project intervention, utilization of a DNP student developed patient referral form. As illustrated in the project's framework, adequate resources and services, or structure, can improve access and utilization. To support this premise, the recruitment of gynecology services from a different location at the onset of the prospective arm of the project improved access to gynecological services for the MU population. While the availability of specialty care services may increase access, care coordination and patient navigation are crucial in improving specialty care utilization Patients who received but did not attend appointments reported that they were unaware that an appointment was scheduled. These findings suggest that specialty care utilization is equally dependent on both the structure and the process. 
Limitations of the application of the theoretical framework were identified. The model failed to consider the influence of external variables and barriers, such as the MU patients' role in specialty care access and utilization. Future studies could incorporate and encourage MU patients as assuming a more active role in the access and utilization of their healthcare.

\section{Limitations}

When drawing conclusions about the scholarly project, the DNP student carefully reexamined the data collection process. Data collection was a complicated process for the DNP student. In gathering the retrospective data, the DNP student found it difficult to determine if patients had received and attended appointments, due to inconsistent and limited documentation of the referral process. The routine provider referral form was often stamped indicating that the form was faxed accompanied by the date of fax, however no documentation of the date of a scheduled appointment or of the patient utilizing the appointment could be found. Therefore, the DNP student had to look at the patient's most recent chart note in attempt to find the information. In the majority of instances, the chart did not yield the referral access or utilization information, and the DNP student had to gain the data from CHC staff members and the MU patients. If the DNP student could not determine whether the patient received an appointment, the patients were omitted from the sample. Omitting patients from the sample, or decreasing the sample size, impacted the project's overall findings. The complexity of the data collection process also highlighted the inconsistencies and potential deficiencies in the CHC's documentation and execution of MU patients' referrals to specialty care services.

Several additional limitations were identified, particularly to the implementation and evaluation of the scholarly project. First, the small sample size from a single facility limited the generalizability of the project's findings. Second, the long-term evaluation of outcomes was limited due to the project's time constraints. Third, the Hawthorne effect, or the chance of participants improving or changing behavior due to the knowledge of being evaluated, must be considered as a likely influence in the observations of increased specialty care utilization. The Hawthorne effect could limit the validity of the project's outcomes.

\section{Nursing implications}

Given the complexity of the healthcare system and the interdependence of processes and players, systems-based strategies are needed to meet the challenges of healthcare access and utilization (IOM, 2015). As an organizational and systems' leader, the Doctor of Nursing Practice (DNP) is poised to develop and evaluate quality improvement initiatives to improve the delivery of safe, accessible, quality, cost-effective healthcare (AACN, 2006). Leadership and research in the implementation and validation of a systems approach can ensure coordinated care that is crucial to the provision of quality, accessible, comprehensive healthcare. With further research, these models can become the standards of care for a coordinated referral process that extends across all healthcare settings and levels of care (IOM 2015).
Little evidence exists that supports the effectiveness of wellstructured safety-net programs and the role of safety-net programs in improving access and utilization tospecialty care services. Further research into specialty care access and utilization for medically underserved would greatly contribute to nursing knowledge. Specifically, research delivery of a larger study that incorporated survival analysis would provide significant outcome data regarding access and utilization of specialty care services. Healthcare reform calls for communities and healthcare systems to assume risk for patient outcomes and healthcare costs. With a greater need for economic considerations in healthcare, CHCs will increasingly be required to demonstrate their value to payors and communities (Horner et al, 2013). This can be achieved through further research that includes economic analyses indicating cost savings through the reduction of unnecessary emergency department visits and hospitalizations. Findings that demonstrate cost savings would promote the support and participation of other players in the healthcare system, thus improving access and utilization among the medically underserved.

The DNP student has many plans to disseminate the findings of this scholarly project. The project will be submitted for publication to a community health journal and presented to the local statistical society. Most importantly, the project will be presented to the local $\mathrm{CHC}$, the specialty care clinics, and other local healthcare forces involved in patient referrals for this community health center. Dissemination of the project's findings will hopefully aid in the recruitment of specialists at the $\mathrm{CHC}$, which in turn can improve specialty care access to the medically underserved.

\section{Summary}

An essential component of the DNP degree is the initiation and evaluation of quality improvement projects that seek to improve healthcare outcomes. The DNP scholarly project sought to evaluate MU patients' access to and utilization of specialty care services in an urban community health center ( $\mathrm{CHC}$ ) before and after the implementation of a clinical practice change, or implementation of the DNP student developed patient referral form. A patient referral form was implemented hopefully to improve MU patients' specialty care access and utilization.

Of the total MU patients referred for specialty care services $(\mathrm{N}=48)$, only half attained access, or received an appointment $(n=26)$. Although implementation of the PRF did not statistically significantly improve MU patients' specialty care access ( $\chi 2$ (1) $=.000, \mathrm{p}>.05$ ), a statistically significant difference was found in MU patients attaining an appointment for a particular specialty service. Specifically, MU patients referred for breast services received appointments at a statistically significant higher rate than all other specialty care referrals $(\chi 2(3)=8.800, p=0.0321)$. This finding was directly attributed to the availability and accessibility of specialty care services on-site at the community health center. To improve specialty care access, the CHC should organize and collaborate with local government or private healthcare systems to form a comprehensive network of specialists. 
The implementation of the PRF did not impact specialty care utilization to a level of statistical significance $(\chi 2(1)=1.4182$, $p=0.2337)$. However, the improvement in the documentation and tracking of referrals was clinically significant. Of the total MU patients that received appointments $(n=26)$, specialty care utilization rates improved by $23 \%$ after PRF implementation due to the increased staff and provider awareness and accountability. A consistent, organized, and systematic method to track and coordinate specialty care referrals is crucial to the development and implementation of organizational strategies to improve healthcare access and utilization. The use of system-based approaches that extend beyond the walls of the CHC can improve collaboration, communication, and connectivity in the coordination of specialty care services. Care coordinators or patient navigators can address these challenges by providing patient support and assistance in navigating through the complex healthcare system.

In the evaluation of MU patients' who received access but did not utilize specialty care services $(n=15)$, linguistic, transportation, and financial concerns were cited as barriers to utilization. The most significant finding was that $48 \%$ reported that they were unaware of their scheduled appointment ( $n=7)$. MU patients reported a lack of knowledge about their scheduled appointments which further emphasized the importance of communication and collaboration between the $\mathrm{CHC}$, referral sites, and patients.

Elements of successful collaboration which will lead to coordinated delivery of healthcare include: (a) assuming accountability, (b) providing patient support, (c) building relationships and agreements among providers (including community agencies) that lead to shared expectations for communication and care; and (d) developing connectivity via electronic or other information pathways that encourage timely and effective information flow between providers (including community agencies) (Improving Chronic Illness Care, 2016). The scholarly project supported the overall goal of coordinated healthcare delivery which is to make appropriate specialty care referrals that meet the six aims of quality healthcare: safe, effective, patient-centered, timely, efficient, and equitable (IOM, 2001).

\section{Acknowledgment}

None.

\section{Conflict of Interest}

No conflict of interest.

\section{References}

1. Moran K, Burson R, Conrad D (2014) The Doctor of Nursing Practice Scholarly Project: A Framework for Success, Jones \& Bartlett Learning, LLC, Burlington, MA, US.

2. Smith JC, Madalia C (2015) Health Insurance in the United States: 2014. US Census Bureau. Washington: US Government Printing Office.

3. Galewitz P (2013) 5.2 million adults will fall into ACA coverage gap next year. Kaiser Health News (KHN).

4. Gulley SP, Rasch EK, Chan L (2011) Ongoing coverage for ongoing care: access, utilization, and out-of-pocket spending among uninsured working-age adults with chronic healthcare needs. American Journal of Public Health 101(2): 368-375.
5. Rhoades JA (2015) Spells of uninsurance: Estimates for the U.S. civilian noninstitutionalized population under age 65, 2013. Statistical Brief \#346, Agency for Healthcare Research \& Quality (AHRQ), Medical Expenditure Panel Survey (MEPS).

6. Knox L, Brach C, Davis M (2015) Primary Care Practice Facilitation Curriculum: Module 5. AHRQ Publication No. 15-0060-EF. Rockville, MD: Agency for Healthcare Research and Quality (AHRQ).

7. Carlson BL, Eden J, O Conner D, Regan J (2001) Primary care of patients without insurance by community health centers. Journal of Ambulatory Care Management 24(2): 47-59.

8. Agency for Healthcare Research and Quality (AHRQ) (2011) Patient Centered Medical Home Resource.

9. Cassidy A (2012) Health policy brief: nurse practitioners and primary care.

10. Goldman LE, Chu PW, Tran H, Stafford RS (2012) Federally qualified health centers and private practice performance on ambulatory care measures. American Journal of Preventative Medicine 43(2): 142-149.

11. National Association of Community Health Centers (NACHC) (2014) Access is the answer: community health centers, primary care \& the future of American healthcare.

12. Neuhausen K, Grumbach K, Bazemore A, Phillips RL (2012) Integrating community health centers into organized delivery systems can improve access to subspecialty care 31(8): 1708-1716.

13. Shi L (2012) The Impact of Primary Care: A Focused Review, Scientifica.

14. Cook NL, Hicks LS, OMalley A J, Keegan T, Guadagnoli E, Landon BE (2007) Access to specialty care and medical services in community health centers. Health Affairs 26(5): 1459-1468.

15. Centers for Disease Control and Prevention (CDC) (2013) Health Insurance Coverage -United States, 2008 and 2010. Morbidity and Mortality Weekly Report (MMWR) 62(3): 61-64.

16. University of Wisconsin Population Health Institute. (2015). County Health Rankings 2015: Louisisana.

17. Horner K, Schaefer J, Wagner E (2013) Care Coordination: Reducing Fragmentation in Primary Care. In: KE Philips \& V Weir (Eds.), Safety Net Medical Home Initiative (2nd), WA: Qualis Health and The MacColl Center for Health Care, Seattle, USA.

18. Moran K, Burson R, Conrad D (2014) The Doctor of Nursing Practice Scholarly Project: A Framework for Success, Jones \& Bartlett Learning, LLC, Burlington, MA, US.

19. Aaronson EL, Marsh RH, Guha M, Schuur JD, Rouhani S A (2015) Emergency department quality and safety indicators in resource-limited settings: an environmental survey. International Journal of Emergency Medicine 8(1): 39.

20. Van Driel ML, De Sutter AI, Christianens TC, De Maeseneer JM (2005) Quality of care: the need for medical, contextual, and policy evidence in primary care. Journal of Evaluation in Clinical Practice 11(5): 417-429.

21. Aday LA, Andersen R (1974) A framework for the study of access to medical care. Health Services Research 9(3):208-220.

22. Grove SK, Burns N, Gray J (2013) The Practice of Nursing Research: Appraisal, Synthesis, and Generation of Evidence ( $7^{\text {th }}$ edn), Elsevier, St. Louis, Missouri, USA.

23. Anyaso HH (2015) Hospitals in states that refuse Medicaid expansion shoulder billions in uncompensated care.

24. Kumar SV (2013) Louisiana health committee rejects Medicaid expansion bill. The Times Picayune.

25. Spatz ES, Phipps MS, LaGarde S, Borgstrom C, Lewis Hunter AE, et al. (2011). Project Access-New Haven: improving access to specialty care for patients without insurance. Connecticut Medicine 75(6): 349-354.

26. Patel K (2016) From worst to first: Louisiana makes great waves with Medicaid expansion. , Brookings. 
27. Hall MA (2013) Organizing uninsured safety-net access to specialist phyician services. Journal of Health Care for the Poor and Underserved 24: 741-752.

28. Landis SE (2002) Buncombe County Medical Society Project Access: Expanding access to care at the local level. North Caroline Medical Journal: 63(1).

29. Nyamathi A, Koniak Griffin D, Greengold BA (2007) Development of nursing theory and science in vulnerable populations research. Annual Review of Nursing Research 25: 3-25.

30. Hall MA (2011) Access to care provided by better safety net systems for the uninsured: Measuring and conceptualizing adequacy. Medical Care Research and Review 68(4):441-461.

31. Institute of Medicine (IOM) (2000) America's Health Care Safety Net: Intact but Endandered. (Lewin, ME \& Altman S Edn.) Washington, DC: National Academies Press (NAP).

32. Soni A (2015) Specialist Need and Access among Adults with Multiple Chronic Conditions, US Civilian Noninstitutuionalized Population, 2012. Rockville, MD: Agency for Healthcare Research and Quality (AHRQ).

33. Aboagye JK, Kaiser HE, Hayanga A J (2014) Rural-urban differences in access to specialist providers of colorectal cancer care in the United States. Journal of American Medical Association (JAMA) Surgery 149(6): 537-543.

34. Isaacs SL, Jellinek P (2007) Is there a (volunteer) doctor in the house? Health Affairs, 26(3): 871-876.

35. Winters R, Pou A, Friedlander P (2011) A "medical mission" at home: the needs of rural American in terms of otolaryngology care. The Journal of Rural Health 27: 297-301.

36. Mortensen K (2014) Access to primary and specialty care and emergency department utilization of Medicaid enrollees needing specialty care. Journal of Health Care for the Poor and Underserved 25(2): 801-813.

37. Taylor EF, Lake T, Nysenbaum J, Peterson G, Myers D (2011) Coordinating Care in the Medical Neighborhood: Critical Components and Available Mechanisms. AHRQ Publication No. 11-0064. Rockville, MD: Agency for Healthcare Research and Quality (AHRQ).

38. Mc Elmurry BJ, Park CG, Buseh AG (2003) The Nurse-Community Health Advocate Team for Urban Immigrant Primary Health Care. Journal of Nursing Scholarship 35(3): 275-281.

39. Hall MA, Hwang W (2010) The costs and adequacy of safety net access for the uninsured: Buncombe County (Ashville), North Carolina.

40. Project Access NOW (2013) Agencies use one-on-one TLC to improve community health, cut costs.
41. Trapp D (2010) Access to care: communities aim to fill health care gap, American Medical News.

42. Yee H (2009) E-Referral: Integrating Information Technology and Clinical Provider Communication to Improve Specialty Care Access and Quality. Power point Presentation, San Francisco General Hospital and Trauma Center, University of California, San Francisco, USA.

43. Rich JT, Neely JG, Paniello RC, Voelker CJ, Nussenbaum B, Wang EW (2010) A practical guide to understanding Kaplan-Meier Curves 143(3): 331-336.

44. Centers for Disease Control and Prevention (CDC) (2013) Health Insurance Coverage -United States, 2008 and 2010. Morbidity and Mortality Weekly Report (MMWR) 62(3): 61-64.

45. Community Hospital Consulting (CHC) \& Willis Knighton Health System (WKHS). (2013). Willis-Knighton Pierremont Health Center. Community Health Needs Assessment.

46. Donabedian A (1988) The quality of care: how can it be assessed? Journal of American Medical Association (JAMA) 260(12): 1743-1748.

47. Health Policy Research Northwest (2010) Project Access NOW: 20082010 Program Evaluation. Eugene, Riverfront Research Park, University of Oregon, Oregon,US.

48. Health Resources and Services Administration (HRSA), US Department of Health and Human Services (US DHHS) (2014) Shortage Designation: Health Professional Shortage Areas \& Medically Underserved Areas/ Populations.

49. Improving Chronic Illness Care (2016) Care Coordination. Retrieved from Improving Chronic Illness Care.

50. Louisiana Hospital Association (LHA)(2014) Hospitals and Louisiana Economy, 2014 Report Highlights.

51. Medicare.gov, The Official US Government Site for Medicare. (n.d.). Retrieved from Physican Compare.

52. (2016) Our views: Medicaid expansion only a first step; challenges to fulfill program's goals not easily removed. The Advocate.

53. US Department of Health and Human Services, Office of Disease Prevention and Health Promotion. (2014). Healthy People 2020 Topics \& Objectives: Access to Health Services.

54.US Department of Veterans Affairs (2015) Veterans Health Administration.

55. Winters R, Pou A, Friedlander P (2011) A "medical mission" at home: the needs of rural American in terms of otolaryngology care. The Journal of Rural Health 27: 297-301. 